\title{
Overcoming Personal Challenges that Rural Teachers Encounter
}

\author{
Dr. PJH Heeralal \\ Senior Lecturer, Department of Science and Technology Education, \\ College of Education, University of South Africa \\ Email: Heerapj@unisa.ac.za
}

\section{Doi:10.5901/mjss.2014.v5n20p1683}

\begin{abstract}
Overcoming challenges that rural teachers encounter is central to educational change in South Africa. The aim of this paper is to examine personal challenges that face rural teachers with a view of offering possible solutions as to how these challenges could be minimised or overcome. Rural teachers were interviewed to ascertain what personal challenges they face. These personal challenges include issues such as logistic arrangements to get to and from school, housing and accommodation, taking care of family needs and engaging in activities for personal and professional growth. Personal challenges that rural teachers encounter have a negative impact on their ability to deliver quality education to learners. This article, by drawing from the experience of the author, as a principal of a rural school in KwaZulu-Natal and by reviewing relevant literature, expounds how the personal challenges faced by rural teachers can be overcome.
\end{abstract}

Keywords: personal challenges, rural.

\section{Introduction}

According to Census 2001, more than $41 \%$ of the population of South Africa lives in rural areas. Thus a large number of schools in South Africa are rural schools, yet surprisingly the education department and universities have not designed or even planned induction programmes for teachers to familiarize themselves with local methods of operation, or for specific teacher training and development needs of rural teachers. Thus according to Saiti, A. (2005)., rural teachers face an unfamiliar school environment and have to make a number of personal adjustments. If teachers work only very unwillingly in remote rural schools, it is probable that their attitudes to their pupils will be negative. Clearly, the more negative the teachers, the more likely it is that pupils will lack motivation and hence fail to achieve their potential.(Saiti, A. 2005). The challenges of improving quality education in rural schools are not just about fixing the schools but are essentially issues of development. Therefore addressing the challenges facing rural schooling will require multi-faceted integrated strategies operating at macro and micro levels that link education interventions with interventions of other government departments, business, civil society, as well as with on-going consultation with, and participation of, educators, learners, parents and communities.

The Department of Education has established a unit within its structures to deal with issues of rural education, however because of the magnitude of the tasks that this unit has, little or no emphasis is placed on the personal challenges that rural teachers encounter. Yet, if personal challenges that rural teachers face is addressed and overcome, it would impact positively on improving the quality of teaching and learning that takes place in rural schools. Hence, the purpose of this paper is to identify personal challenges that rural teachers encounter, and examine how these challenges can be overcome.

\section{Challenges Facing Rural Education in South Africa}

The challenges experienced by rural communities are well captured in the research by the Nelson Mandela Foundation and been summarised as follows:

- Lack of basic services (water, electricity, roads, sanitation) affect access to and quality of schooling

- Inadequate physical and infrastructure conditions of schools - buildings, toilet facilities, telecommunications and equipment a problem

- Distances travelled to school - children walk long distances, and no adequate transport provision available

- Quality of education in rural schools- lack of qualified teachers, irrelevance of curriculum, large classes, lack of teaching aids, higher learner/educator ratios are a major challenge 
- Curriculum relevance - need for Maths Science and Technology, understanding of local and global environment, need to promote critical thinking, need for useful skills

- Approaches to learning - rote learning still rife, no understanding of teachers and text books, teachers largely use monologue although exceptions exist

- Curriculum 2005 - teacher qualifications, large classes, limited resources learners do not understand teachers and text books, expensive to implement, confusing

- Language of teaching and learning a barrier

- Lack of Early Childhood Development (ECD) education

- Lack of capacity of School Governing Bodies

- Poverty- cost of fees and uniforms a barrier to education (low salaries parents)

- Competing priorities between education and domestic chores (child labour) undermine support for schooling

- Hunger, sickness and diseases affecting education

- High attrition and drop out rate at secondary level

- Educational disparities for girls and boys infringing the right to education

- Practice of corporal punishment is extensive

- Inappropriate conditions of service for teachers

- District support is minimal

- Role of traditional leaders and concept of democracy to be understood in context

Although a long list of challenges facing rural education has been identified, little or no mention is made of the personal challenges that teacher face in rural areas. This is a cause for concern, because teacher challenges, if identified and addressed can assist in overcoming many of the above mentioned challenges, as teachers a major role players in the delivery of quality education in South Africa

\section{Types of Challenges Facing Rural Schools}

There are three types of challenges facing rural schools - basic, communication and other drawbacks.

\subsection{Basic Challenges}

These are problems that urban schools consider basic, while their rural counterparts consider them insurmountable hurdles. These are issues that rural schools need to overcome before any communication facilities and resources can be put in place to improve their access to quality education. (Herselman 947)

\subsection{Lack of school buildings and stationery}

This is the most basic need when it comes to schooling, because without proper school buildings and stationery it becomes virtually impossible for learners to receive adequate teaching. There are many rural schools that do not have adequate school buildings and stationery for learners to use, because of the partial subsidy the state provides for building costs. The rest of the costs must be borne by the community. Most rural schools reside in areas with extreme poverty and therefore there is unlikely to be extra funds for buildings and resources (Jenkin, 1995, p. 3).

\subsection{Remotely situated rural schools}

The isolation of rural schools from the urban education mainstream is another obstacle to overcome. Most rural schools reside in inaccessible areas, which make it difficult for resources and facilities to reach them. There are also limited transport resources to these areas, where scholars usually walk long distances to school. When it rains these rural 'gravel' roads become dangerous to travel on and because there are limited communication resources at these rural schools they get left behind and forgotten. This is one of the main drawbacks facing rural schools (Jenkin, 1995, p. 3).

\subsection{Lack of experienced and skilled teachers}

It is no surprise to find that the most experienced and skilled teachers reside in the urban areas. This is largely due to the availability and accessibility of relevant resources and facilities. The disturbing fact is that out of 360700 educators in South Africa, $70 \%$ of them ply their trade in rural schools. This means that the majority of teachers are operating in less 
than ideal conditions. The result is that the majority of scholars are receiving education of inferior quality by teachers without the appropriate facilities and resources needed to sufficiently teach (Jenkin, 1995, p. 1).

\subsection{Communication Challenges}

These are problems that rural schools need to overcome if they want to compete both locally and globally. Schools that do not have communication facilities face being left behind in the dark ages (pre computers). If rural schools want to make use of the Internet, chat rooms, bulletin boards and academic web sites then they have no option but to improve their communication facilities to be able to log on to the Internet.

\subsection{Lack of telephone facilities}

Telephone facilities will make it possible for schools in rural areas to keep abreast with the latest developments in the educational field. It will make it possible for schools in rural areas to log on to the Internet and exchange information with their urban counterparts. It will help rural schools improve their access of information and knowledge (Jenkin, 1995, p. 3).

\subsection{Lack of computer hardware and software}

Computers and computer resources are indispensable in the educational and business environment today. It is very difficult for someone who is not computer literate to successfully complete his or her tertiary studies or find gainful employment. Most jobs in the business world require some knowledge of the use of computers and the Internet. According to Furlonger, $(2002$, p. 2) in most rural schools it is unlikely that you will find a computer lab, yet alone someone with knowledge of the Internet, unlike urban schools. Yet the Internet could be used to bridge the gap between rural and urban schools, through the use of educational web sites and lectures via satellite. The computer and its resources are central to modern education and it's here to stay.

\subsection{Lack of technical training}

Many schools in rural areas lack teachers with appropriate technical skills and experience in key subjects like computer literacy and Internet usage. This results in most rural schools not being able to offer computer courses, resulting in rural scholars not being adequately prepared for tertiary studies where computers and the Internet knowledge are indispensable. This makes the gap between rural scholars and their urban counterparts all the much greater when competing for tertiary positions (Jenkin, 1995, p. 3).

\subsection{Other Challenges}

These are other issues that will hinder rural schools bridging the education divide between themselves and urban schools. They are secondary problems that rural schools need to master before they can be judged equally with schools in urban areas.

\subsection{Lack of library facilities}

The library is a common resource in most urban schools and areas. According to Burnett $(1999, \mathrm{p} .3)$, most rural communities do not even know what a library is yet alone what its function is. Establishing a library in schools in rural areas will help improve the illiteracy rate and enhance rural education. These libraries can eventually evolve to include computers to help train scholars in computer literacy.

\subsection{Lack of transport facilities}

According to Jenkin $(1995$, p. 3), it is not uncommon for scholars to walk long distances to school in rural areas. Giving rural scholar's access to transport resources will motivate them to attend school as a large majority of them walk long distances to school everyday in all kinds of weather. This is largely due to poverty, limited schools available in rural areas and lack of appropriate transport facilities. These are just some of the main reasons why there are a large number of children who do not attend school in rural areas (Jenkin, 1995. p. 2). 


\subsection{Large student to teacher ratio}

According to Jenkin $(1995$, p. 2), it is not uncommon for schools in rural areas to have class sizes of up to 70 scholars to a teacher. This is also a problem in some urban 'government' schools, where they too have high scholars to teacher ratios. This results in the weaker scholars in the class not getting the necessary attention that is needed, since the teacher has so many scholars to attend to. Jenkin $(1995$, p. 3) also asserts that the drop out and repetition rates in rural schools are very high

Studies comparing working conditions for teachers in rural and other kinds of school settings have found differences in average class size and in the mix of courses taught, particularly at the secondary level.

\section{Possible Solutions}

A rural solution in uplifting rural schools is a solution that results in positive changes and conditions in rural schools. It is a solution that must produce positive results for rural schools and their communities.

\subsection{Teacher recruitment and retention.}

Attracting and retaining quality teachers will be critical in creating and implementing higher standards for student academic achievement. The problem is one of distribution. Causes for a teacher shortage in rural areas include: social and cultural isolation, poor pay and salary differentials, limited teacher mobility, lack of personal privacy, rigid lockstep salary schedules and monetary practices, the luring of teachers away by higher paying private sector businesses and industries, strict teacher certification and licensure practices and tests, lack of reciprocal certification and licensure to enable teaching in another state, recruitment cost (time/costs to gather information), and a high rate of teacher turnover ( $30 \%$ to $50 \%$ in some areas).

\subsection{Strategies to redress deployment imbalances}

Policy makers have tried a number of strategies to redress the imbalances in teacher deployment. The main strategies can be categorized as:

- Incentives for teachers locating in rural areas

- Forced transfer of teachers

- Targeted recruitment

\subsection{Incentives}

Some countries have attempted to make working in rural areas more attractive through the use of incentives. In some cases these may be financial incentives, in the form of a hardship allowance, travel allowance, or subsidised housing. In other areas the incentives may be non-monetary, including, for example, special study leave or better training opportunities (Gaynor, 1998, p17; Craig, Kraft \& Plessis, 1998).

\section{Methodology}

A qualitative approach was used to gather data for the study. Five rural teachers were purposively sampled. These teachers had homes and a family in urban areas but worked in rural schools. For the duration of the school term they resided the rural areas surrounding the school. The teachers were interviewed using an interview schedule. The interviews were transcribed and analysed using a thematic approach.

\section{Findings}

Interviews with rural teachers identified the following personal challenges that rural teachers encounter:

Rural teachers are away from families for prolonged periods of time (1 week, 2 weeks, month, and term), children of the teachers do not get to spend time with their teacher parents. They are virtually reared/brought up by uncles and aunts, grandparents, nannies and even strangers. Often female teachers have to leave their newborns in the care family members and nannies in order to per sue their careers or just earn sufficient money to raise a family. This places a strain 
on family life since a stable family unit is the main building block of any stable society.

Rural teachers have to travel long distances to schools and incur more travel expenses than other teachers. They also spend more time travelling to and from school. If they do not have their own vehicles, which is the case for most rural teachers, availability of transport, and reliability of the public transport system can pose challenging to teachers. Often teachers have to walk long distances to remote school, where there are no access roads to the schools, crossing flooded rivers, and risking their lives to get to school.

Teachers board with families or rent accommodation from families surrounding their school. Rural teachers seldom have the privacy and anonymity of living far away from the schools in which they work, and their behaviour is scrutinized more closely, making them vulnerable to community pressure (Goddard \& Habermann, 2001),

Their living conditions are terrible - they live in mud huts, have no running water and electricity, poor toilet facilities, no place to wash and cook and have to fetch water from rivers. There is a lack of shopping facilities in the rural area, and goods are expensive, they do not have refrigerators - food stuff goes off.

Teachers have to take time off for sickness of family members, death in the family and they experience difficulty in making funeral arrangements for deceased family members. When they become sick, health facilities are very far away from them. A visit to a doctor that might take a day in an urban area, can involve an absence of three or four days in the rural area.

The teachers have to deal with community issues such as feuding families where they board. They get unnecessarily involved in personal lives of family members where they board.

The teachers experience financial difficulties, having to maintain two households. They cannot make a meaningful contribution to the community in which the teacher lives permanently. Holidays and vacations are taken up attending to matters that were neglected in the course of the year. The rural teacher, when on vacation is in essence not on vacation, which leads to stress.

Studying and professional development suffers because of distance from universities and discussion classes.

\section{Discussion}

\subsection{Overcoming personal challenges}

Overcoming personal challenges that rural teachers encounter need the concerted effort by school management and leadership. Intervention to overcome the personal challenges needs to involve principals, the school governing body and the Department of Education.

Within the schools themselves, steps could be taken to offset some of the currently discouraging conditions. For example, modern telecommunications and computing technologies can reduce schools' need to rely on teachers in the classroom.

The personal challenges faced by teachers may differ from school to school, hence school principals need to identify the particular challenges faced at their school and together with teachers, governing bodies and local school authorities, find solutions to overcome the personal challenges that their teachers encounter. This may involve:

\subsection{Changing school times to ensure that teachers who travel long distances can be accommodated.}

The South African Schools Acts makes provision for the delegation of certain duties or responsibilities to school governing bodies. One such responsibility is the determination of school times. Hence to overcome the problem of late coming of teachers who travel long distances to get to school, school times can be adjusted to accommodate late coming. Obviously time that is lost has to be covered. This can be done by moving the closing time backwards (closing school later in the afternoons). Many teachers travel to school from their homes on a Monday, reside in the immediate vicinity of the school from Monday to Thursday and return home on a Friday. These teachers will want to leave school early on a Friday. They are only too willing to work slightly longer hours from Tuesday to Thursday in order to gain concessions on Mondays and Fridays. If principals and school governing bodies engage with the teachers on adjustment of school times, the issue of late coming on Mondays and early leaving on Fridays can be resolved.

\subsection{Making provision in the time table for teachers who have to travel long distances to and from school.}

If a school does not want to interfere with normal school times to accommodate late coming of teachers, it can opt to make provision in the time table to accommodate teachers who might come late to school because of having to travel 
long distances to school. The non-teaching time of the affected teachers can be programmed in the morning sessions on Mondays and in the afternoons on Fridays. Often schools do not want to address these issues in ways that the presenter has proposed, late coming teachers classes are left unattended or management may merely insist that teachers get up earlier and travel to school on time. This affects teacher moral, motivation and attitudes. Yet if the school engages the teachers on these issues and tries to accommodate them, teachers become motivated, they develop a positive attitude which can contribute to more effective teaching and learning to take place at the school.

\subsection{Transport}

Where teachers experience difficulties with regards to transport problems, making special arrangement with public transport and taxi operators to accommodate the special needs at a school can easily alleviate the problem. In addition, where teachers walk long distances to school, they may tend to start late, and finish early. As transport difficulties often make supervision visits from inspectors less frequent in isolated schools, there is little to prevent a gradual erosion of the school year. Many rural teachers are in locations away from their families or their home areas. Travel from remote rural areas can be time consuming, and travel to meet their families. If the school is in a remote location, trips often involve absences on Fridays or Mondays.

\subsection{Housing}

Engaging local housing authorities to address housing needs is always in the best interest of the school and community, negotiating with private individuals to make available housing for teachers can also assist in resolving the issue of teacher housing. Developing a database of parents who offer housing for rent is yet another direction that school management can take to address housing needs of teachers. The SGB can be of assistance in this respect. A second major incentive for teachers to locate in rural areas is the provision of teacher housing. Where teachers cannot live near the school, they are likely to spend a lot of time traveling, often to the detriment of their school work. Housing is particularly important for female teachers. In Malawi, the EMIS data reveals a strong association between the availability of housing in an area and the presence of female teachers in the school. Similarly in Uganda, a recent Study on Primary School Teachers Attrition considered provision of housing to be a key factor in ensuring teacher retention especially in rural areas. Currently $15 \%$ of the School Facilities Grants (SFG) is allocated to the construction of teachers' houses.

\subsection{Feeling of isolation}

Living and teaching in a rural school can make the teacher feel isolated. Schools need to organise activities for teachers, including professional development activities so that they keep in touch with latest developments

\subsection{Making school facilities available after hours}

Often the school has the amenities and facilities that may be lacking in the community and places where teachers live or board. The school can make these amenities and facilities to the teachers so that some of the challenges that they face can be overcome

\subsection{Providing incentives}

Schools in rural areas are often already disadvantaged and it becomes very difficult for the school or governing body to offer their teachers incentives that are offered to teachers in urban and ex Model C schools, however principals and governing bodies need to make attempts to secure funds in an attempt to offer incentives to teachers, in order to offset the personal challenges that they experience as a result of teaching in a rural school.

\subsection{Negotiation with dept. officials for concession/special dispensation}

Policy makers and government need to give serious consideration to introduce policy and even legislation specially designed for rural schooling, in order to negate the disadvantages that are associated with rural education. If this happens, it will assist in alleviating the challenges that rural teachers encounter and improve the quality of teaching and learning that takes place in rural schools 


\subsection{Issues of personal and professional growth}

Teachers in rural areas are far removed from institutions of higher learning. The best they can do is to enrol for distance education courses. Coupled with the many other challenges that they face, these teachers have study by correspondence. Distance learning institutions are moving more and more into using ICT to deliver their courses. Rural schools need to allow their teachers to use the schools electronic facilities to pursue their studies.

\subsection{Offering higher salaries}

Another option would be to offer higher wages and benefits to teachers who are willing to work in hard-to-staff schools. The drawbacks associated with rural school teaching could, in theory, be offset by higher wages or improved benefits, or both, thereby improving the ability of officials in these areas to recruit and retain teachers comparable to their peers in other schools.

There is a need to develop deployment policies that ensure sufficient teachers in remote schools. Successful strategies seem likely to require a combination of accurate information about deployment and teacher movements and policies that require or encourage rural location. Some of the promising options include:

\section{Recommendations}

For the department of education to respond to the personal challenges that rural teachers encounter the Education Management Information System (EMIS) survey that they conduct annually needs to capture information on challenges that they face.

Principals need to do on site situational analysis on personal challenges that teachers at their schools encounter, attempt to resolve issues and thereby improve productivity and the quality of teaching and learning that takes place in rural schools.

The information that they gather should be communicated to the department of education so that the department of education can act on it.

South Africa can learn from the experiences of how other African countries have responded to the challenges that rural teachers experience.

\section{Conclusion}

Relatively recent research suggests that teacher attitudes to appointment in rural schools have changed, and that many rural teachers see a brighter side of rural life: safer and more connected to nature; plenty of clean, open spaces and absence of incidence of crime and other vices prevalent in cities provide a good place to raise children; a smaller more caring community; and absence of bureaucratic layers allows for direct, verbal communication (Boylan \& McSwan, 1998; Kannapel \& DeYoung, 1999; Stanford, 2001

\section{References}

Boylan, C. \& McSwan, D. (1998) Long-staying rural teachers: who are they? Australian Journal Education, 42(1), 49-65.

Clarke, S., \& Wildy, H. (2011). Improving the small rural or remote school: The role of the district. Australian Journal of Education, 55(1), 24-36. Retrieved from EBSCOhost.

Cobbold, C. (2006). Attracting and retaining rural teachers in Ghana: the premise and promise of a district sponsorship scheme. Journal of Education for Teaching, 32(4), 453-469. doi:10.1080/02607470600982142

Goddard, J. T. \& Habermann, S. R. (2001) Accessing the knowledge base of retired teachers: experiences in establishing a formal mentoring program in a rural school division, Journal of Research in Rural Education, 17(2), 92-101.

Informing Science In SITE - "Where Parallels Intersect" June 2003 Paper Accepted as a Short Paper ICT in Rural Areas in South Africa: Various Case Studies ME Herselman Technikon Pretoria, Pretoria, South Africa

Jenkin, T. (1995). The rural development strategy of the government of national unity. Retrieved 4 June 2002 from http://www.polity.org.za/govdocs/rdp/rural17.html

Kannapel, P. J. \& DeYoung, A. J. (1999) The rural school problem in 1999: a review and critique of the literature, Journal of Research in Rural Education, 15(2), 67-79.

McEwan, P. J. (1999) Recruitment of rural teachers in developing countries: an economic analysis, Teaching and Teacher Education, 15(8), 849-859. Ministerial Seminar on Education for Rural People in Africa: Policy Lessons, Options and Priorities hosted by the 
Government of Ethiopia Addis Ababa, Ethiopia, 7-9 September 2005

Monk, D. (2007). Recruiting and retaining high-quality teachers in rural areas. The Future Of Children / Center For The Future Of Children, The David And Lucile Packard Foundation, 17(1), 155-174. Retrieved from EBSCOhost.

Rural Education - Overview, International Context - Schools, School, Teachers, and America State University.com.file:///C:/ Documents\%20and\%20Settings/heerapj/My\%20Documents/rural\%2010.mht\#ixzz1cLJhMQr9

Saiti, A. (2005). The staffing of small rural primary schools in Greece. Management in Education (Education Publishing Worldwide Ltd), 19(4), 32-36. Retrieved from EBSCOhost.

Stanford, B. H. (2001) Reflections of resilient, persevering urban teachers, Teacher Education Quarterly, 28(3), $75-87$. 